\title{
Differential Effects of Sport Type and Sport Category on Time Demands and Well-Being of College Athletes
}

\author{
Jay C. Santos ${ }^{1, *}$, Michael Sagas ${ }^{2}$ \\ ${ }^{1}$ Department of Psychology, Central Luzon State University, Science City of Muñoz, Nueva Ecija, Philippines \\ ${ }^{2}$ Department of Sport Management, University of Florida, Gainesville, Florida, United States
}

Received November 3, 2021; Revised December 6, 2021; Accepted January 16, 2022

Cite This Paper in the following Citation Styles

(a): [1] Jay C. Santos, Michael Sagas, "Differential Effects of Sport Type and Sport Category on Time Demands and Well-Being of College Athletes," International Journal of Human Movement and Sports Sciences, Vol. 10, No. 1, pp. 22 - 30, 2022. DOI: 10.13189/saj.2022.100104.

(b): Jay C. Santos, Michael Sagas (2022). Differential Effects of Sport Type and Sport Category on Time Demands and Well-Being of College Athletes. International Journal of Human Movement and Sports Sciences, 10(1), 22 - 30. DOI: 10.13189/saj.2022.100104.

Copyright $\mathrm{C} 2022$ by authors, all rights reserved. Authors agree that this article remains permanently open access under the terms of the Creative Commons Attribution License 4.0 International License

\begin{abstract}
Time commitment of college athletes raises some alarm, leaving them vulnerable to career transitions and well-being consequences. How college athletes spend their academic and athletic time is not much explored. In the United States, college athletes are often classified based on their respective sport revenue production and sport type. The comparison of athletes based on sport category and sport type is sparse in the academic literature. By and large, well-being and time commitment of athletes among some others are believed to be significant factors in college sports success. This study examined the differential effects of sport category (revenue vs non-revenue) and sport type (individual vs team) on academic time use, athletic time use, subjective well-being, emotional well-being, and physical well-being of college athletes. It utilized secondary data provided by the U.S. National Collegiate Athletic Association (NCAA) granted upon agreement on data fair use. Multivariate Analysis of Variance (MANOVA) was performed to examine the research questions. Significant differences relative to sport type and sport category were found in academic time use and athletic time use. Team sport and revenue-generating sport athletes were more athletically inclined, while individual sport and non-revenue generating sport athletes were more academically engaged.
\end{abstract}

Keywords Time Use, College Athletes, Well-Being, Academic Engagement, Athletic Engagement, NCAA

\section{Introduction}

Survey results of the 2015 administration of the National Collegiate Athletic Association (NCAA) Growth, Opportunities, Aspirations, and Learning of Students in college (GOALS) revealed that time use by student-athletes continues to rise based on median weekly time spent in academics and athletics during the season [1]. Time demands on athletics and academics as previously reported are indeed among the primary challenges that college athletes deal with [2-3].

The situation of college athletes is not, however, prototypical. Division affiliation, for instance, results to varying level of athletic experience, with Division I schools offering more benefits such as athletic scholarship, a grant that is non-existent in Division III. In addition, NCAA student-athletes are often categorized based on revenues their sports produce. Division I men's basketball and football are referred to as the revenue-generating sports [4], while the rest fit as non-revenue-generating sports. This encapsulates the highly commercialized treatment on men's basketball and football [5].

\section{Sport Category}

Revenue and non-revenue sport student-athletes differ in their engagement in athletics and academics. This is evident on the study of freshmen student-athletes in four universities [6]. Contrasting results come afloat between the two groups such that non-revenue sport student-athletes 
were found more engaged academically and were reported to have better grades, while revenue sport student-athletes were deemed more inclined in athletics and they displayed higher athletic identity. Chen and colleagues [7] noted that student-athletes in the revenue sports of men's basketball and football studied less and practiced more compared to their non-revenue sport peers.

Interestingly, media attention given to college sports differs according to sport category. Games of revenue sports, especially football, are regularly covered by national media entities, including TV networks, while games of non-revenue sports are rarely covered by national media, except for conferences and championship games. Harrison and colleagues [4] posited that significant media attention is one of the defining characteristics of revenue sports. Thus, the well-being of non-revenue sport athletes is arguably better than their revenue sport peers.

On the claim that the experience of student-athletes differs relative to sport category, Paule and Gilson [8] argued that the experience of non-revenue sport student-athletes is similar to the experience of student-athletes in revenue sports. They suggested that the benefits undermine the challenges associated with intercollegiate athletics. This conclusion supported the earlier contention of Potuto and O'Hanlon [9] that the college experience of student-athletes in non-revenue sports does not differ with the experience of those in revenue sports.

\section{Sport Type}

How athletes from individual and team sports differ across several outcomes of interest has been fully supported in frames of research. Wellness is one. Zhou et al. [10] examined the relationship between alcohol consumption and selected psychosocial variables as function of sport type of student-athletes in the U.K. Significant in their findings was that team sport student-athletes tend to be happier than individual sport student-athletes. Remarkably, Zhou and colleagues did not find a significant association between alcohol consumption and happiness. In another study of elite Australian athletes, Lastella et al. [11] concluded that team sport athletes have better sleep quality than individual sport athletes, although both groups failed to achieve the recommended eight hours of sleep on a daily basis.

Individual and team sport athletes also contrast in personality characteristics. Individual sport athletes were found to possess more positive personality characteristics, such as perseverance, positivity, resilience, self-esteem, and self-efficacy than team sport athletes [12]. Notably, team sport athletes scored significantly higher in agreeableness and sociotropy [13] and extraversion [14].

Affiliation to a specific sport type goes with some implications. Research revealed that individual sport athletes tend to engage in risky behaviors than their team sport counterparts [15]. In addition, individual sport athletes are more likely to adapt sport psychology skills such as imagery [16], an indication that the effects of psychological skills are perceived better in sports that do not require coordination with another or multiple players. Fundamentally, engagement in individual sports is physically safer, since injury incidence is lower in individual sports than in team sports [17].

\section{College Athletes' Time Demands}

Presumably, student-athletes spend more time than what countable rule allows. Findings from the PAC-12 [18] survey revealed that student-athletes averaged 50 hours per week on athletic tasks during their competition season, and the travel for competitions impedes them to have adequate time for study and sleep. Further, results from the NCAA [1] GOALS revealed that student-athletes spend between 28.5 hours and 34 hours every week, based on the median, on athletic activities during their competition season. During the off-season, at least half of them reported that they spend as much or more time as they do during the competition season, an indication that their athletic time commitments are consistent throughout the whole year. No other type can go near the approximate amount of time spent in athletic activities by student-athletes, making them the atypical college students [19].

Relatively few studies directly investigated how college athletes spend their academic time demands. Chen et al. [7] looked into the case of student-athletes who logged their daily time use for six weeks. They found that GPA is positively associated with time used for classes and studying, and their participants reported spending about six hours for classes and studying per day. Woodruff and Schallert [20] estimated that they spend between 8 hours to 36 hours on academic activities. They concluded that the amount of time and the process by which student-athletes spend their time influence their perception of sense of self and motivation. Lee et al. [21] compared the daily life activities of student-athletes and non-athletes and ascertained that student-athletes spend lesser time in schoolwork $(6.4 \%$ of wake hours) than non-athletes (22.8\%).

\section{Subjective Well-Being}

Diener, Suh, Lucas, and Smith [22] defined subjective well-being as a "broad category of phenomena that includes people's emotional responses, domain satisfactions, and global judgments of life satisfaction" (p. 277). Diener [23] theorized that subjective well-being is composed of three primary components - positive affect, negative affect, and life satisfaction. He added that because subjective well-being depends on the time of assessment, it can be conceptualized as either a relatively stable or momentary state. 
The positive effects of subjective well-being are well-known. For instance, individuals who rate their subjective well-being high tend to have better health outcomes [24]. Subjective well-being has also been linked to longevity [25]. The research literature is consistent in stating that subjective well-being is enhanced by physical activity engagement [26]. In the context of sports, subjective well-being has been commonly used as an outcome variable. Involvement in sports can reap positive benefits [27], one being its effect on subjective well-being.

\section{Physical Well-Being}

In reference to the extensive time use of student-athletes [1], it can be argued that they are prone to physical exhaustion or fatigue. Their unique college experience means that they must deal with the mental and physical challenges of academic and athletic tasks. College athletes identified physical exhaustion as a concern and pinpointed the competition season as stressful; adding that a hypothetical 2-3 break after the season would help them recover from the physical and mental toll of the season [18].

Engagement in physical activity, including sports, has been found to predict physical well-being. In fact, it is believed that sport motivation leads to better physical health outcomes [30]. Evidence in the extant literature, though, is inconsistent. Putting forward, the mere presence of physical education and sport in schools brings positive development to students in various aspects such as on the physique, lifestyle, and affection, as well as in social and cognitive domains [29]. It was claimed that the physical health of adolescent athletes is better than that of their non-athlete counterparts [30]. Noteworthy though, Watson and Kissinger [31] compared the wellness level of student-athletes and non-athletes but found no significant differences between the two groups in their level of physical wellness. A systematic review of studies that compared the body image concerns of female student-athletes and non-athletes revealed that student-athletes reported more apprehensions on their physical condition and appearance [32]. This finding indicates that athletic status is a risk factor for female students in college. In another study, the risky health behaviors of student-athletes and non-athletes were compared [33]. The findings demonstrated that while non-athletes are more likely to drink and smoke more than student-athletes do, student-athletes were more prone to disordered eating. In similar respect, student-athletes were noted to have higher risk of joint health concerns in the long run [34]. Predominantly, the risk of developing physical health issues has been magnified among former student-athletes who played in collision sports [35] such as football.

\section{Emotional Well-Being}

Physical activity such as sport and exercise promises a lot of gains. To illustrate, a previous study noted the effects of physical exercise as a buffer against anxiety, depression and stress [36]. One benefit is on emotional well-being, which has been claimed to facilitate positive development among adolescents [37].

Keyes [38] defined emotional well-being as "a cluster of symptoms reflecting the presence or absence of positive feelings about life" (p. 208). Past research shows that the positive impact of physical activity on emotional well-being traverse different populations, including adolescents [40] and college students [41].

Several studies have investigated the emotional well-being of athletes. Highly notable among the findings is that emotional well-being is influenced by social and individual factors. Solberg and Havari [42] framed their study on self-determination theory to investigate the relationship of autonomy and motivation with emotional well-being among Olympic-level athletes. They found that emotional well-being is positively associated with perceived autonomy support, autonomy, and intrinsic goal motivation. This indicates that athletes who felt supported and were motivated by their own goals reported higher emotional well-being. In one study, Ntoumanis and colleagues [43] examined the role of motivational climates on emotional well-being of adolescent athletes aged 12-16 years using a longitudinal design. They concluded that emotional well-being is positively predicted by peer task-involving climate but negatively predicted by coach ego-involving climate. It is inherent in their findings that emotional well-being is influenced by the type of environment athletes live in. Meanwhile, Adie et al. [44] explored the impact of sport competition on emotional well-being of adult-aged club-level athletes. They deduced that challenge/threat appraisal of an athletic event is positively related to emotional well-being. They therefore articulated that athletes who perceive athletic competition as a chance to showcase growth and mastery of skills are more likely to experience a higher level of emotional well-being.

\section{Research Questions}

Studies have been done on student-athletes' well-being but none so far has directly explored the connection between well-being and time use of NCAA student-athletes. Accordingly, this current research examined the role of academic and athletic time use on the well-being of student-athletes. The need to explore on the well-being specific to the group of student-athletes has been afloat given their unique context and the interplay of culture on well-being [45]. The comparison of college athletes' time demands and well-being through the lens of sport type and sport category must find esteemed place in the academic literature. Thus, the following research questions were examined:

RQ1: Do the levels of academic time use, athletic time use, subjective well-being, emotional well-being, and 
physical well-being significantly differ when assessed according to sport type?

RQ2: Do the levels of academic time use, athletic time use, subjective well-being, emotional well-being, and physical well-being significantly differ when assessed according to sport category?

\section{Materials and Methods}

\section{Participants}

This study utilized the NCAA GOALS 2015 dataset provided by the NCAA Research granted upon data use agreement by both parties. The Institutional Review Board approval of the university was a requirement prior to the release of the data. The authors were given access to a sample of 21,219 respondents. A random sample of 5,042 respondents using the Statistical Package for Social Sciences (SPSS) was selected for this study. A majority of the respondents were members of non-revenue $(\mathrm{n}=4673$; $92.7 \%)$ and team sports $(\mathrm{n}=3645 ; 72.3 \%)$. Swimming, golf, tennis, track, wrestling, and gymnastics were categorized as individual sports, while baseball, football, ice hockey, lacrosse, soccer, crew/rowing, field hockey, softball, and volleyball were treated as team sports. It should be recognized, however, that while some sports have team elements (e.g., relay events), sports such as track/cross country and swimming are classified as individual sports. Football and men's basketball teams at the Division I level were categorized as revenue sports while the remaining sports were treated as non-revenue sports. This typology is consistent in the published literature [4].

\section{Measures}

Academic time use and athletic time use are the predictor variables in the current study. Academic time use contains the approximate time spent in all academic-related tasks, including attendance to classes and study time for courses. Athletic time use denotes the approximate time devoted for practices, trainings, competition, and all athletic-related activities, such as meeting with coaches, team functions, and film study sessions. Both time use variables pertained to the athletes' self-reported estimated hours spent per week during the competition season.

The dependent variables consist of a three-item physical well-being, two-item emotional well-being, and three-item subjective well-being, developed by the NCAA through their GOALS research program and validated by Santos
[46]. A 5-point scale was used for the items in the three indicators of well-being. Means were used for all indicators.

Three items measured subjective well-being (SWB), which included "In the last month, how often have you felt that things were going your way?", "In the last month, how often have you felt about your ability to handle your personal problems?", and "All things considered, how happy are you today?" Participants answered these items using a 5 -point scale $(1=$ very often; $2=$ fairly often; $3=$ sometimes; $4=$ almost never; $5=$ never). The Cronbach's alpha of this measure is .64 [46].

Two items, "In the last month, how often have you felt difficulties were piling up so high that you could not overcome them?" and "In the last month, how often have you felt that you were unable to control the important things in your life?", captured emotional well-being (EWB). Both items were answered using the five categories of very often, fairly often, sometimes, almost never, and never. A modest .77 is the Cronbach's alpha attached to this measure [46].

Three items, "During the last 30 days, how many days did you have headache?", "During the last 30 days, how many days did you have a cold, flu or similar illness?", and "During the last 30 days, how many days did you have trouble sleeping?" measured physical well-being (PWB). The items in this variable used the five categories of 15+ days, 8-14 days, 4-7 days, 1-3 days, and none. The Cronbach's alpha is recorded at .58 [46].

\section{Data Analysis}

To test the research questions, a 2 × 2 MANOVA table was utilized to project mean differences in academic time use, athletic time use, subjective well-being, emotional well-being, and physical well-being by sport type (individual vs team) and sport category (revenue vs non-revenue). The means, standard deviations, and $F$ values were reported. Significance levels were set at $p$ $<.05$.

\section{Results}

The $2 \times 2$ MANOVA in Table 1 shows how the mean scores in time use and well-being variables differ for sport type and sport category. On the average, individual sport athletes spend 2.2 hours more in academics but 3.1 hours less in athletics than team sport athletes. Non-revenue sport athletes spend 5.09 hours more in academics but 4.37 hours less in athletics compared to their revenue sport peers. 
Table 1. 2 × 2 MANOVA on the time use and well-being variables

\begin{tabular}{|c|c|c|c|c|c|c|}
\hline & \multicolumn{3}{|c|}{ Sport Type } & \multicolumn{3}{|c|}{ Sport Category } \\
\hline & $\begin{array}{l}\text { Individual } \\
(n=1397) \\
\end{array}$ & Team $(n=3645)$ & & $\begin{array}{l}\text { Revenue } \\
(n=369)\end{array}$ & $\begin{array}{c}\text { Non-revenue } \\
(n=4673)\end{array}$ & \\
\hline & $M(S D)$ & $M(S D)$ & $F$ & $M(S D)$ & $M(S D)$ & $F$ \\
\hline Academic time use & $42.72(15.57)$ & $40.52(15.90)$ & $19.46^{* *}$ & $36.41(16.64)$ & $41.50(15.71)$ & $35.64 * * *$ \\
\hline Athletic time use & $32.71(14.46)$ & $35.81(15.63)$ & $41.45 * * *$ & $39.00(16.83)$ & $34.63(15.21)$ & $27.74 * * *$ \\
\hline Subjective well-being & $2.90(.52)$ & $2.91(.55)$ & .09 & $2.88(.58)$ & $2.91(.54)$ & .36 \\
\hline Emotional well-being & $3.20(1.03)$ & $3.18(1.04)$ & .79 & $3.08(1.14)$ & $3.20(1.03)$ & $4.36^{*}$ \\
\hline Physical well-being & $4.00(.84)$ & $3.98(.90)$ & .89 & $3.97(1.01)$ & $3.99(.88)$ & .13 \\
\hline
\end{tabular}

Note. $M=$ means. $S D=$ standard deviation.

$* * * p<.001$

$* * p<.01$

$* p<.05$

Significant sport type differences were found in academic time use, $F(1,5040)=19.46, p<.001$, and athletic time use, $F(1,5040)=41.45, p<.001$. Specifically, student-athletes from individual sports have significantly higher academic time use $(M=42.72 ; S D=15.57)$ than student-athletes in team sports $(M=40.52 ; S D=15.90)$. Meanwhile, team sport student-athletes devote significantly more athletic time use $(M=35.81 ; S D=15.63)$ than individual sport student-athletes $(M=32.71 ; S D=$ 14.46).

In sport category, significant differences were found in academic time use, $F(1,5040)=35.64, p<.001$, athletic time use, $F(1,5040)=27.74, p<.001$, and emotional well-being, $F(1,5040)=4.36, p=.037$. Specifically, non-revenue sport student-athletes have significantly higher academic time use $(M=41.50 ; S D=15.71)$ and better emotional well-being $(M=3.20 ; S D=1.03)$ than revenue sport student-athletes. Revenue sport student-athletes commit significantly more time in athletics $(M=39 ; S D=16.83)$ than their non-revenue sport peers $(M=34.63 ; S D=15.21)$.

\section{Discussion}

This study examined the differential effects of sport category and sport type on academic time use, athletic time use, subjective well-being, emotional well-being, and physical well-being. Significantly, engagement of student-athletes in academics and athletics differ relative to sport type and sport category.

Comparison of means revealed the significant sport type and sport category differences in academic time use and athletic time use. Athletes from individual sports have higher academic time use and lower athletic time use than team sport student-athletes. Non-revenue sport student-athletes reported higher time commitment in academics and less time in athletics than their revenue sport counterparts. Thus, student-athletes from individual and non-revenue sports are more academically engaged while their counterparts in team and revenue-sports are more athletically inclined. These findings are in conjunction with available literature. Student-athletes in the revenue sports of men's basketball and football have more time in athletics and less time in academics compared to their non-revenue sport counterparts [7]. This puts forward that revenue sport student-athletes are more athletically inclined, while non-revenue sport student-athletes are more academically engaged [6].

One reason for the disproportionate athletic engagement of revenue sports among student-athletes lies on the notion that they are only one step away from getting drafted to play professional sports. The odds are small with an estimated $2 \%$ of the hundred thousand of student-athletes every year to turn professional [47], however, this does not alter the fact that those in men's basketball and football possess the highest chance of being selected to play professional sports compared to all other student-athletes in other sports. Annually, most of the players drafted in the NBA and NFL come from the Division I level equivalent sports [48]. Indicatively, the differential effects of sport category on the engagement of student-athletes in academics and athletics expose the contradictory value that is present in intercollegiate athletics. Placing more emphasis on athletics at the expense of academics seems to be a function of a prevailing culture in the intercollegiate athletics environment. While there is a claim that athletics enhances the campus culture [49], concerns relating to academics and commercialization of intercollegiate sports also exist [50]. Despres and cohorts [51] summed it up when they described "college athletics as a cultural phenomenon, in which student-athletes are required to place more emphasis on sports than on academics" (p. 201). These studies brought to the fore the connection of sport category to the prevailing culture of intercollegiate athletics in general.

Comeaux [52] implicated that the preference of athletics over academics in college sports is systemic in nature. He argued that the academic-athletic divide in intercollegiate athletic environment already exists and is being propagated by the stakeholders of college sports, most specifically the NCAA and its member institutions. For instance, athletic 
scholarships are available among Division I schools and limited among Division II schools, but are not provided to Division III institutions, which means that Division III prospects are usually recruited, if they are at all, mainly on academic merits and the athletic abilities come secondary. In contrast, athletic engagement can be elucidated through various levels. On the micro level are the coaches. Innate to coaching is the pressure to perform and win. For Division I coaches, most especially in the revenue sports of men's basketball and football, there exists additional pressure because they usually have the biggest contracts, financially and length wise. Consequently, job security within these demographics is of utmost priority. As such, while it may be claimed that the academics of their student-athletes take precedence over anything else, the pressure to win changes the perspective. Financial incentive is not a motive in emphasizing academics as research suggests that improved academic performance of student-athletes does not result to better coaches' salary [53]. Among the stakeholders of college athletics, coaches have the most significant relationship with the student-athletes [54]. Thus, the influence of college coaches in the academic and athletic engagement of student-athletes should be regarded. Research indicates that coaches provide a learning environment for student-athletes $[55,56]$. It is possible that coaches, knowingly and unknowingly, convey their preference between academics and athletics to their student-athletes, which then results to how the student-athletes choose to utilize their academic and athletic time.

On the institutional level, the role of organizational culture can be invoked. Although athletic administrators identified academic excellence as top priority of their departments [57], several studies reflected that academics are not the top priority of big-time college sports [58], usually referring to Division I schools among the three divisions and to men's basketball and football among the sports. Eitzen [27] delved on the assertion that schools winning national championships have higher enrolment and media publicity and that there is remarkable increase in alumni donations to the athletic programs. On the same note, Anderson [59] articulated that success in college athletics has some positive effects to the athletic department in micro level and to the academic institution in the macro sphere. These gains include boost in donations, improved academic reputation, increased applications and enrolment, and better quality of applicants. On the individual level, the expectations of student-athletes themselves deserve introspection. According to an NCAA report, most Division III student-athletes cited academics as their primary reason for choosing their school [60]. On the upper hand, most student-athletes in Divisions I and II indicated that athletics is their primary reason. Athletic scholarships are available in Divisions I and II, paving the way to grants-in-aid. Moreover, the same report embodied the dynamics of identification regarding academic and athletic engagement. Those who view themselves as athletes more than students spend more time in athletics by an average of five hours but spend less time on academics by an average of six hours. Personal expectations and perceptions seem to pose interplay.

\section{Conclusions}

Student-athletes from individual and non-revenue sports are more academically engaged while their counterparts in team and revenue-sports are more athletically inclined. This poses the academic-athletic divide in terms of sport category and sport type. The context of being revenue sports and team sports athletes requires them enormous time as function of their settings. Student-athletes from revenue sports and team sports disproportionately spend more time in athletics over academics. This establishes its own culture; prioritizing athletics over academics gets normal, as it becomes inherent in the intercollegiate athletics environment.

\section{Acknowledgements}

We are thankful to the NCAA Research. Due acknowledgements go to Keke Liu and Lydia Bell, and to the reviewers and editors for the refinement of this manuscript.

\section{REFERENCES}

[1] National Collegiate Athletic Association, "GOALS Association Wide Slides from 2020 Convention", NCAA GOALS Study, https://www.ncaa.org/about/resources/rese arch/ncaa-goals-study (accessed Dec. 1, 2020)

[2] Galli, N., \& Reel, J. J., "Can good come from bad? An examination of adversarial growth in Division I NCAA athletes," Journal of Intercollegiate Sport, vol. 5, no. 2, pp. 199-212, 2012, DOI: 10.1123/jis.5.2.199.

[3] Menke, D. J., "Inside the bubble: College experiences of student-athletes in revenue-producing sports," Journal for the Study of Sports and Athletes in Education, vol. 10, no. 1, pp. 16-32, 2016, DOI: 10.1080/19357397.2016.1160695.

[4] Harrison, C., Rasmussen, J., Connolly, C., Janson, N., Bukstein, S., \& Parks, C., "Diggin' deeper into the culture of revenue sports," Journal for the Study of Sports and Athletes in Education, vol. 4, no. 3, pp. 325-332, 2010, DOI: 10.1179/ssa.2010.4.3.325.

[5] Sanderson, A. R., \& Siegfried, J. J., "The national collegiate athletic association cartel: Why it exists, how it works, and what it does," Review of Industrial Organization, vol. 52, no. 2, pp. 185-209, 2018, DOI: 10.1007/s11151-017-9590$\mathrm{z}$. 
[6] Comeaux, E., Speer, L., Taustine, M., \& Harrison, C. K., "Purposeful engagement of first-year Division I student-athletes," Journal of the First-Year Experience \& Students in Transition, vol. 23, no. 1, pp. 35-52, 2011.

[7] Chen, S., Mason, N., Middleton, S., \& Salazar, W., “An examination of behavioral data and testing scores as indicators of student-athletes' academic success," Kentucky Association of Health, Physical Education, Recreation and Dance, vol. 51, no. 1, pp. 34-43, 2013.

[8] Paule, A. L., \& Gilson, T. A., "Current collegiate experiences of big-time, non-revenue, NCAA athletes," Journal of Intercollegiate Sport, vol. 3, no. 2, 333-347, 2010 .

[9] Potuto, J. J. R., \& O'Hanlon, J., "National study of student-athletes regarding their experiences as college students," College Student Journal, vol. 41, no. 4, pp. 947, 2007.

[10] Zhou, J., Heim, D., \& O'Brien, K., “Alcohol consumption, athlete identity, and happiness among student sportspeople as a function of sport-type," Alcohol and Alcoholism, vol. 50, no. 5, pp. 617-623, 2015, DOI: 10.1093/alcalc/agv030.

[11] Lastella, M., Roach, G. D., Halson, S. L., \& Sargent, C. "Sleep/wake behaviours of elite athletes from individual and team sports," European Journal of Sport Science, vol. 15, no. 2, pp. 94-100, 2015, DOI: 10.1080/17461391.2014. 932016.

[12] Laborde, S., Guillén, F., \& Mosley, E., "Positive personality-trait-like individual differences in athletes from individual-and team sports and in non-athletes," Psychology of Sport and Exercise, vol. 26, pp. 9-13, 2016, DOI: 10.1016/j.psychsport.2016.05.009.

[13] Nia, M. E., \& Besharat, M. A., "Comparison of athletes' personality characteristics in individual and team sports," Procedia-Social and Behavioral Sciences, vol. 5, pp. 808-812, 2010, DOI: 10.1016/j.sbspro.2010.07.189.

[14] Eagleton, J. R., McKelvie, S. J., \& De Man, A., "Extra version and neuroticism in team sport participants, individual sport participants, and nonparticipants," Perceptual and Motor Skills, vol. 105, no. 1, pp. 265-275, 2007, DOI: $10.2466 \% 2 F p m s .105 .1 .265-275$.

[15] Giannopoulou, I., Noutsos, K., Apostolidis, N., Bayios, I., \& Nassis, G. P., "Performance level affects the dietary supplement intake of both individual and team sports athletes," Journal of Sports Science \& Medicine, vol. 12, no. 1, pp. 190-196, 2013.

[16] Kizildag, E., \& Tiryaki, M. Ş., "Imagery use of athletes in individual and team sports that require open and closed skill," Perceptual and Motor Skills, vol. 114, no. 3, pp. 748-756, 2012, DOI: 10.2466/05.20.22.PMS.114.3.748-75 6.

[17] Theisen, D., Frisch, A., Malisoux, L., Urhausen, A., Croisier, J. L., \& Seil, R., "Injury risk is different in team and individual youth sport," Journal of Science and Medicine in Sport, vol. 16, no. 3, pp. 200-204, 2013, DOI: 10.1016/j.jsams.2012.07.007.

[18] Pacific Coast Conference 12, "PAC-12 report on student-athlete time demands," Student-Athlete Health and Well-Being Initiative, https://pac-12.com/student-athlete-h ealth-well-being-initiative (accessed Dec. 1, 2020)
[19] Kissinger, D. B., Newman, R., Miller, M. T., \& Nadler, D. P., "Athletic identity of community college student athletes: Issues for counseling," Community College Journal for Research and Practice, vol. 35, no. 7, pp. 574-589, 2011, DOI: $10.1080 / 10668920801897886$.

[20] Woodruff, A. L., \& Schallert, D. L., "Studying to play, playing to study: Nine college student-athletes' motivational sense of self," Contemporary Educational Psychology, vol. 33, no. 1, pp. 34-57, 2008, DOI: 10.1016/j.cedpsych.2007.04.001.

[21] Lee, H. J., Park, H. R., \& Shin, H. K., "Comparison of daily life activity experiences between student athletes and nonathletes in a college," Research Quarterly for Exercise and Sport, vol. 78, no. 1, pp. 93-94, 2007.

[22] Diener, E., Suh, E. M., Lucas, R. E., \& Smith, H. L., "Subjective well-being: Three decades of progress," Psychological Bulletin, vol. 125, no. 2, pp. 276-302, 1999.

[23] Diener, E., "Subjective well-being: The science of happiness and a proposal for a national index," American Psychologist, vol. 55, no. 1, pp. 34-43, 2000, DOI: 10.1037/0003-066X.55.1.34.

[24] Roysamb, E., Tambs, K., Reichborn-Kjennerud, T., Neale, M. C., \& Harris, J. R., "Happiness and health: environmental and genetic contributions to the relationship between subjective well-being, perceived health, and somatic illness," Journal of Personality and Social Psychology, vol. 85, no. 6, pp. 1136-1146, 2003, DOI: 10.1037/0022-3514.85.6.1136.

[25] Pressman, S. D., \& Cohen, S., "Use of social words in autobiographies and longevity," Psychosomatic Medicine, vol. 69 , no. 3, pp. 262-269, 2007, DOI: 10.1097/PSY.0b01 3e31803cb919.

[26] Carels, R. A., Berger, B., \& Darby, L., "The association between mood states and physical activity in postmenopausal, obese, sedentary women," Journal of Aging and Physical Activity, vol. 14, no. 1, pp. 12-28, 2006, DOI: $10.1123 /$ japa.14.1.12.

[27] Eitzen, D. S. "Fair and foul: Beyond the myths and paradoxes of sport," Rowman \& Littlefield, 2016.

[28] Tebbe, D. Relationships among academic and athletic motivation and mental, physical, and academic outcomes in collegiate athletes [dissertation], University of Texas at Arlington; 2017.

[29] Bailey, R., "Physical education and sport in schools: A review of benefits and outcomes," Journal of School Health, vol. 76, no. 8, pp. 397-401, 2006, DOI: 10.1111/j.1746-15 61.2006.00132.x.

[30] Snyder, A. R., Martinez, J. C., Bay, R. C., Parsons, J. T., Sauers, E. L., \& McLeod, T. C. V., "Health-related quality of life differs between adolescent athletes and adolescent nonathletes," Journal of Sport Rehabilitation, vol. 19, no. 3, pp. 237-248, 2010, DOI: 10.1123/jsr.19.3.237.

[31] Watson, J. C., \& Kissinger, D. B., "Athletic participation and wellness: Implications for counseling college student athletes," Journal of College Counseling, vol. 10, no. 2, pp. 153-162, 2007.

[32] Varnes, J. R., Stellefson, M. L., Janelle, C. M., Dorman, S. M., Dodd, V., \& Miller, M. D., "A systematic review of 
studies comparing body image concerns among female college athletes and non-athletes, 1997-2012," Body Image, vol. 10, no. 4, pp. 421-432, 2013, DOI: 10.1016/j.bodyim.2013.06.001.

[33] Pritchard, M. E., Milligan, B., Elgin, J., Rush, P., \& Shea, M., "Comparisons of risky health behaviors between male and female college athletes and non-athletes," Athletic Insight, vol. 9, no. 1, pp. 67-78, 2007.

[34] Sorenson, S. C., Romano, R., Scholefield, R. M., Martin, B. E., Gordon, J. E., Azen, S. P., \& Salem, G. J., "Holistic life-span health outcomes among elite intercollegiate student-athletes," Journal of Athletic Training, vol. 49, no. 5, pp. 684-695, 2014, DOI: 10.4085/1062-6050-49.3.18.

[35] Simon, J. E., \& Docherty, C. L., "Current health-related quality of life in former National Collegiate Athletic Association Division I collision athletes compared with contact and limited-contact athletes," Journal of Athletic Training, vol. 51, no. 3, pp. 205-212, 2016, DOI: $10.4085 \% 2 \mathrm{~F} 1062-6050-51.4 .05$.

[36] Salmon, P., "Effects of physical exercise on anxiety, depression, and sensitivity to stress: A unifying theory," Clinical Psychology Review, vol. 21, no. 1, pp. 33-61, 2001, DOI: 10.1016/S0272-7358(99)00032-X.

[37] Park, N., "The role of subjective well-being in positive youth development", The Annals of the American Academy of Political and Social Science, vol. 591, no. 1, pp. 25-39, 2004, DOI: 10.1177/0002716203260078.

[38] Keyes, C. L., "The mental health continuum: From languishing to flourishing in life," Journal of Health and Social Behavior, vol. 43, no. 2, pp. 207-222, 2002, DOI: 10.2307/3090197.

[39] Lubans, D. R., Plotnikoff, R. C., \& Lubans, N. J., “A systematic review of the impact of physical activity programmes on social and emotional well - being in at risk youth", Child and Adolescent Mental Health, vol. 17, no. $1, \quad$ pp. 2-13, 2012, DOI: 10.1111/j.1475-3588.2011.00623.x.

[40] Spruit, A., Assink, M., van Vugt, E., van der Put, C., \& Stams, G. J., "The effects of physical activity interventions on psychosocial outcomes in adolescents: A meta-analytic review", Clinical Psychology Review, vol. 45, pp. 56-71, 2016, DOI: 10.1016/j.cpr.2016.03.006.

[41] Giacobbi Jr, P. R., Tuccitto, D. E., \& Frye, N., "Exercise, affect, and university students' appraisals of academic events prior to the final examination period", Psychology of Sport and Exercise, vol. 8, no. 2, pp. 261-274, 2007, DOI: 10.1016/j.psychsport.2006.04.001.

[42] Solberg, P. A., \& Halvari, H., "Perceived autonomy support, personal goal content, and emotional well-being among elite athletes: Mediating effects of reasons for goals", Perceptual and Motor Skills, vol. 108, no. 3, pp. 721-743, 2009, DOI: 10.2466/PMS.108.3.721-743.

[43] Ntoumanis, N., Taylor, I. M., \& Thøgersen-Ntoumani, C., "A longitudinal examination of coach and peer motivational climates in youth sport: Implications for moral attitudes, well-being, and behavioral investment," Developmental Psychology, vol. 48, no. 1, pp. 213, 2012, DOI: $10.1037 / \mathrm{a} 0024934$

[44] Adie, J. W., Duda, J. L., \& Ntoumanis, N., “Achievement goals, competition appraisals, and the psychological and emotional welfare of sport participants", Journal of Sport and Exercise Psychology, vol. 30, no. 3, pp. 302-322, 2008, DOI: $10.1123 /$ jsep.30.3.302.

[45] Diener, E., "Assessing well-being: The collected works of Ed Diener," Springer, 2009.

[46] Santos, J. C., "Antecedents and Consequences of College Athletes' Time Demands", Unpublished doctoral dissertation, 2020

[47] National Collegiate Athletic Association, "NCAA recruiting facts: College sports create a pathway to opportunity for student-athletes," Recruiting - Eligibility Center, https://www.ncaa.org/student-athletes/future/recrui ting (accessed Dec. 1, 2020)

[48] National Collegiate Athletic Association, "Estimated probability of competing in professional athletics," https://www.ncaa.org/about/resources/research/estimated-p robability-competing-professional-athletics (accessed Dec. 1, 2019)

[49] Latz, A., \& Mulvihill, T., "Relationships between coaches and parents of female field hockey athletes", Journal for the Study of Sports and Athletes in Education, vol. 3, no. 1, pp. 19-40, 2009, DOI: 10.1179/ssa.2009.3.1.19.

[50] Custis, T., Hoben, M., \& Larsen, P., "Big money, corruption, and black markets", Sport, Business and Management, vol. 9, no. 4, pp. 399-415, 2019, DOI: 10.1108/SBM-09-2018-0070.

[51] Despres, J., Brady, F., \& McGowan, A. S., "Understanding the culture of the student - athlete: Implications for college counselors", The Journal of Humanistic Counseling, vol. 47, no. 2, pp. 200-211, 2008, DOI: 10.1002/j.2161-1939.2008. tb00058.x.

[52] Comeaux, E., "The student (less) athlete: Identifying the unidentified college student," Journal for the Study of Sports and Athletes in Education, vol. 1, no. 1, pp. 37-44, 2007, DOI: 10.1179/ssa.2007.1.1.37.

[53] Fogarty, K., Soebbing, B. P., \& Agyemang, K. J., "NCAA Division I-FBS salary determinants: A look at new and amended contracts", Journal of Issues in Intercollegiate Athletics, vol. 8, no. 1, pp. 123-138, 2015.

[54] Good, R. C. Ways in which participation in intercollegiate athletics contributes to the learning and development of student-athletes [dissertation]. Illinois State University; 2015

[55] Mastroleo, N. R., Marzell, M., Turrisi, R., \& Borsari, B., "Do coaches make a difference off the field? The examination of athletic coach influence on early college student drinking", Addiction Research \& Theory, vol. 20, no. 1, pp. 64-71, 2012, DOI: 10.3109/16066359.2011.5626 21.

[56] Steinfeldt, J. A., Foltz, B. D., Mungro, J., Speight, Q. L., Wong, Y. J., \& Blumberg, J., "Masculinity socialization in sports: Influence of college football coaches", Psychology of Men \& Masculinity, vol. 12, no. 3, pp. 247-259, 2011, DOI: $10.1037 / \mathrm{a} 0020170$.

[57] Cooper, C., Weight, E. A., \& Fulton, N., "Investigating organizational core values in NCAA athletic departments", 
Sport, Business and Management, vol. 5, no. 1, pp. 50-64, 2015, DOI: 10.1108/SBM-05-2011-0051.

[58] Jayakumar, U. M., \& Comeaux, E., "The cultural cover-up of college athletics: How organizational culture perpetuates an unrealistic and idealized balancing act", The Journal of Higher Education, vol. 87, no. 4, pp. 488-515, 2016, DOI: 10.1080/00221546.2016.11777411.
[59] Anderson, M. L., "The benefits of college athletic success: An application of the propensity score design," Review of Economics and Statistics, vol. 99, no. 1, pp. 119-134, 2017, DOI: 10.1162/REST_a_00589.

[60] National Collegiate Athletic Association. "GOALS and SCORE studies", https://www.ncaa.org/score-study, (accessed Dec. 31, 2020) 